\title{
Pengujian Karakteristik Laston Lapis Antara Menggunakan Batu Gunung Sopai Kabupaten Toraja Utara
}

\author{
Henry Gunawan *1, Alpius*2, Charles Kamba*3 \\ *1 Mahasiswa Program Studi Teknik Sipil, Universitas Kristen Indonesia Paulus, Makassar, Indonesia \\ henrygunawan19@gmail.com \\ *2 Dosen Program Studi Teknik Sipil, Universitas Kristen Indonesia Paulus, Makassar, Indonesia \\ alpiusnini@gmail.com \\ *3 Dosen Program Studi Teknik Sipil, Universitas Kristen Indonesia Paulus, Makassar, Indonesia \\ kamba.charles@gmail.com
}

\begin{abstract}
ABSTRAK
Penelitian berikut menguji karakteristik Campuran Laston Lapis Antara menggunakan batu Gunung Sopai Kabupaten Toraja Utara. Menurut tes laboratorium metode yang digunakan dalam penelitian ini adalah melakukan beberapa uji karakteristik yaitu agregat kasar, agegat halus, filler dengan aspal, lalu desain komposisi tersebut dan kemudian menguji Marshall dengan campuran Laston pada lapisan tengah atau antara dan kadar aspal yang optimal, diperoleh sisa kestabilan Marshall dari campuran tersebut. Hasil penelitian yang dilakukan dalam Laboratorium Jalan serta Aspal Fakultas Teknik Jurusan Teknik Sipil Universitas Kristen Indonesia Paulus Makassar, tunjukkan karakteristik material bentuk kekerasan jalan batuan Sopai di Kabupaten Toraha Utara telah memenuhi Ketentuan Umum Bina Marga Tahun 2018, sebagai pelapis muka jalan. Melalui uji Marshall didapat karakter campur Laston Lapis Antara pada kadar 5\%, $5,5 \%, 6 \%, 6,5 \%$ dan 7\%. Hasil uji perendaman Marshall campuran Laston Lapis Antara untuk kadar aspal terbaik $5,50 \%$, sisa kestabilan Marshall adalah 98,83\% masuk dalam standard Bina Marga 2018 minimal 90\%
\end{abstract}

Kata kunci : Karakteristik, Laston Lapis Antara, Marshall

\begin{abstract}
This study was intended to test the characteristics of the Laston Lapis Antara mixture using the rock of Mount Sopai, North Toraja Regency. According to Laboratory tests, this research used method carry out part of series of characteristic test on the coarse of aggregate, fine of aggregate, filler then asphalt, and composition design of the mix, when do the Marshall testing with the Laston mixture in the middle or intermediate layer and the optimal bitumen content, the residual is obtained. Marshall stability of the mixture. Road and Asphalt Laboratory of Civil Engginering, Christian University of Indonesia Paulus, show that the characteristics of the sampel material of Sopai rocks in North Toraja Regency have met the General Provisions of Bina Marga 2018, as a road surface coating. Through the marshall test, the characteristics of the Laston Lapis Antara Mixture were obtained with pitch levels of $5.00 \%, 5.50 \%, 6.00 \%, 6.50 \%$ and $7.00 \%$. the results of the Marshall Laston Lapis Antara mix immersion test with the best asphalt content of $5.50 \%$, the remaining Marshall stability is $98.83 \%$ which meets the general specifications of Bina Marga 2018 at least $90 \%$.
\end{abstract}

Keywords: Characteristics, Laston Intermediate Layer, Marshall Immersion

\section{PENDAHULUAN}

Mengingat pentingnya dan fungsi jalan untuk mendorong distribusi barang dan jasa. Laston adalah lapis permukaan konstruksi jalan terdiri dari campuran aspal dan agregat, dicampur, aspal, dan dipadatkan pada suhu tinggi. Campuran Laston membutuhkan penggunaan proses pencampuran yang memenuhi persyaratan spesifikasi aspal dan agregat. Agregat memiliki peran penting dalam penbemtukan lapisan perkerasan, dan daya dukung perkerasan sangat bergantung pada karakteristik agregat. Oleh karena itu, sebelum menentukan bahwa agregat dapat digunakan sebagai bahan pengerasan jalan, properti dari agregat harus diperiksa dengan cermat. Kementerian Pekerjaan Umum dan Perumahan Rakyat (PUPR) mendorong pengguan material lokal secara preferensial. Agara bias cukup kebutuhan tersebut maka perlu adanya pemanfaatan sumber daya alam pada sekitar bangun jalan. Gunung sopai di kabupaten Toraja Utara merupakan salah satu kawasan yang memiliki sumber daya alam berupa material batuan. Keberadaan material pada Gunung Sopai Kabupaten Toraja Utara masih tergolong cukup untuk digunakan sebagai bahan dasar lapisan permukaan jalan. Material pada gunung Sopai belum dimanfaatkan secara luas sehingga penggunaan batu gunung Sopai sejauh ini hanya 
Paulus Civil Engineering Journal

E- Jurnal Teknik Sipil UKI-Paulus Makassar

http://ojs.ukipaulus.ac.id/index.php/pcej

digunakan oleh warga sekitar untuk bahan bangunan skala kecil seperti pondasi dan sebagainya.

Tujuan penelitian untuk mengetahui nilai karateristik batu Gunung Sopai, karakteristik aspal dan berat jenis filler untuk campuran beraspal, mengetahui komposisi campuran Laston Lapis Antara yang menggunakan agregat batu Gunung Sopai, sehingga didapatkan nilai karakteristik campuran Laston Lapis Antara dengan melalui pengujian Marshall Konvensional dan mengetahui nilai Stabilitas Marshall Sisa (\%) pada Marshall Immersion yang menggunakan agregat batu Gunung Sopai.

Adapun penelitian terkait yang dipublikasikan Kadar serat ijuk 2\% untuk campuran AC-BC memiliki nilai perendaman 94,04\% [1], agregat Sungai Wanggar yang digunakan dalam campuran AC-BC memiliki nilai indeks perendaman $94,41 \%$ [2], penggunaan limbah abu bata ringan sebagai filler untuk pengisi kadar aspal 5,7\% memiliki nilai stabilitas tinggi [3], penggunaan slag nikel untuk campuran HRS-Base dalam tes Marshall menghasilkan nilai 97,03\% [4], penggunaan LGA sebagai pengganti aspal minyak memiliki indeks perendaman 95,21\% [5], penambahan semen meningkatkan durabilitas dan stabilitas [6].

Penelitian yang terkait yaitu agregat sungai Masanda dengan aspal penetrasi 60/70 untuk agregat kasar $42,64 \%$, agregat halus $45,45 \%$, semen (Filler) $5,41 \%$ dengan kadar aspal optimum $6,50 \%$ dimana penelitian tersebut memenuhi standar yang telah ditentukan oleh Bina Marga. [7],
Volume 3 No.2, Juni, 2021 ISSN Online 2775-4529 ISSN Print 2775-8613

agregat sungai Bangkanase dengan aspal penetrasi 60/70 untuk agregat kasar 42,82\%, agregat halus $45,73 \%$, semen (Filler) $5,45 \%$ dengan kadar aspal optimum $6,00 \%$ dimana penelitian tersebut memenuhi standar yang telah ditentukan oleh Bina Marga. [8] bahwa komposisi campuran untuk Laston AC-BC agregat kasar yaitu $43,13 \%$, agregat halus (pasir) $46,19 \%$, filler $5,53 \%$, dan aspal 5,14\%. Untuk campuran Laston AC-WC agregat kasar yaitu $37,05 \%$, agregat halus (pasir) $50,60 \%$, filler $5,85 \%$ dan aspal 6,50\%. [9]

\section{METODE}

\section{Lokasi Pengambilan Material dan Waktu Penelitian}

Agregat yang digunakan berasal dari Gunung Sopai yang dapat dilihat pada Gambar 1.

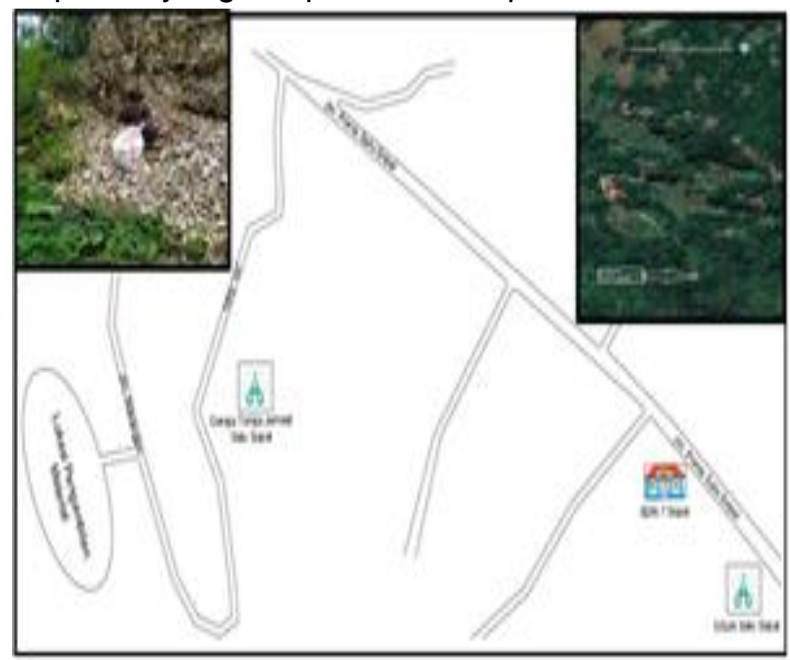

Gambar 1. Peta lokasi pengambilan material

\section{Pemeriksaan Karakteristik Agregat dan Berat Jenis Filler}

Tabel 1. Hasil pengujian karakteristik agregat dan berat jenis filler

\begin{tabular}{|c|c|c|c|c|c|c|c|}
\hline \multirow{2}{*}{ No } & \multirow{2}{*}{$\begin{array}{c}\text { Jenis } \\
\text { Pemeriksaan }\end{array}$} & \multirow{2}{*}{ Metode } & \multicolumn{2}{|c|}{ Spesifikasi } & \multirow{2}{*}{ Satuan } & \multirow{2}{*}{$\begin{array}{c}\text { Hasil } \\
\text { Penelitian }\end{array}$} & \multirow{2}{*}{ Keterangan } \\
\hline & & & Min & Maks & & & \\
\hline \multirow{5}{*}{1} & Keausan Agregat & \multirow{5}{*}{$\begin{array}{c}\text { SNI } 2417- \\
2008\end{array}$} & \multirow{5}{*}{ - } & \multirow{5}{*}{40} & \multirow{5}{*}{$\%$} & & \multirow{5}{*}{ Memenuhi } \\
\hline & Fraksi A & & & & & 7 & \\
\hline & Fraksi B & & & & & 6,6 & \\
\hline & Fraksi C & & & & & 5,9 & \\
\hline & Fraksi D & & & & & 4,36 & \\
\hline \multirow{3}{*}{2} & Berat Jenis dan & SNI & & & & & \multirow{3}{*}{ Memenuhi } \\
\hline & Penyerapan Agregat & 1969- & & & & & \\
\hline & Kasar & 2016 & & & & & \\
\hline
\end{tabular}




\begin{tabular}{|c|c|c|c|c|c|c|c|}
\hline & Bulk & \multirow{11}{*}{$\begin{array}{c}S N I \\
1970- \\
2016\end{array}$} & 2,5 & - & & 2,65 & \multirow{11}{*}{ Memenuhi } \\
\hline & SSD & & 2,5 & - & & 2,68 & \\
\hline & Apparent & & 2,5 & - & & 2,74 & \\
\hline & Penyerapan & & - & 3 & & 1,36 & \\
\hline \multicolumn{6}{|c|}{ Berat Jenis dan } & & \\
\hline & \multicolumn{5}{|l|}{ Penyerapan Agregat } & & \\
\hline & Halus & & & & & & \\
\hline & Bulk & & 2,5 & - & & 2,623 & \\
\hline & SSD & & 2,5 & - & & 2,668 & \\
\hline & Apparent & & 2,5 & - & & 2,748 & \\
\hline & Penyerapan & & - & 3 & & 1,730 & \\
\hline 3 & Analisa Saringan & \multirow{13}{*}{$\begin{array}{c}\text { SNI } \\
\text { ASTM } \\
\text { C136- } \\
2012\end{array}$} & & & & & \multirow{13}{*}{ Memenuhi } \\
\hline & $1 "$ & & \multicolumn{2}{|c|}{100} & \multirow{12}{*}{$\%$} & 100 & \\
\hline & $3 / 4 "$ & & 90 & 100 & & 94,03 & \\
\hline & $1 / 2 "$ & & 75 & 90 & & 88,69 & \\
\hline & $3 / 8 "$ & & 66 & 82 & & 77,26 & \\
\hline & No. 4 & & 46 & 64 & & 59,39 & \\
\hline & No. 8 & & 30 & 49 & & 45,22 & \\
\hline & No. 16 & & 18 & 38 & & 35,22 & \\
\hline & No. 30 & & 12 & 28 & & 25,26 & \\
\hline & No. 50 & & 7 & 20 & & 17,13 & \\
\hline & No. 100 & & 5 & 13 & & 10,59 & \\
\hline & No. 200 & & 4 & 8 & & 6,14 & \\
\hline & PAN & & - & - & & 0.00 & \\
\hline 4 & Berat Jenis Filler & $\begin{array}{c}\text { SNI 03- } \\
1969- \\
1990\end{array}$ & 2,5 & - & & 3,09 & Memenuhi \\
\hline 5 & $\begin{array}{l}\text { Material Lolos Saringan } \\
\qquad 200\end{array}$ & $\begin{array}{c}S N I \\
A S T M \\
C 117: 201 \\
2\end{array}$ & - & 10 & $\%$ & 6,2 & Memenuhi \\
\hline \multirow{2}{*}{6} & Sand Equivalent & $\begin{array}{c}S N I \\
03: 4428: 1 \\
997\end{array}$ & 50 & - & $\%$ & 97,337 & Memenuhi \\
\hline & Nilai Setara Pasir & $\begin{array}{c}\text { SNI 03- } \\
4428- \\
1997\end{array}$ & - & 5 & & 2,663 & Memenuhi \\
\hline \multirow{10}{*}{7} & Partikel Pipih & \multirow{5}{*}{$\begin{array}{c}\text { ASTM } \\
\text { D4791-10 }\end{array}$} & & & & & \\
\hline & $3 / 4$ & & \multirow{4}{*}{-} & \multirow{4}{*}{10} & \multirow{4}{*}{$\%$} & 9,72 & \multirow{4}{*}{ Memenuh } \\
\hline & $1 / 2$ & & & & & 8,65 & \\
\hline & $3 / 8$ & & & & & 7,66 & \\
\hline & $1 / 4$ & & & & & 0.00 & \\
\hline & Partikel Lonjong & \multirow{5}{*}{$\begin{array}{c}\text { ASTM } \\
D-4791- \\
10\end{array}$} & & & & & \multirow{5}{*}{ Memenuhi } \\
\hline & $3 / 4$ & & \multirow{4}{*}{-} & \multirow{4}{*}{10} & \multirow{4}{*}{$\%$} & 9,74 & \\
\hline & $1 / 2$ & & & & & 9,49 & \\
\hline & $3 / 8$ & & & & & 4,20 & \\
\hline & $1 / 4$ & & & & & 0.00 & \\
\hline 8 & Kelekatan Agregat & SNI 2439- & 95 & - & $\%$ & $>98$ & Memenuhi \\
\hline
\end{tabular}




\section{Pemeriksaan Karakteristik Aspal}

Tabel 2. Pemeriksaan karakteristik aspal

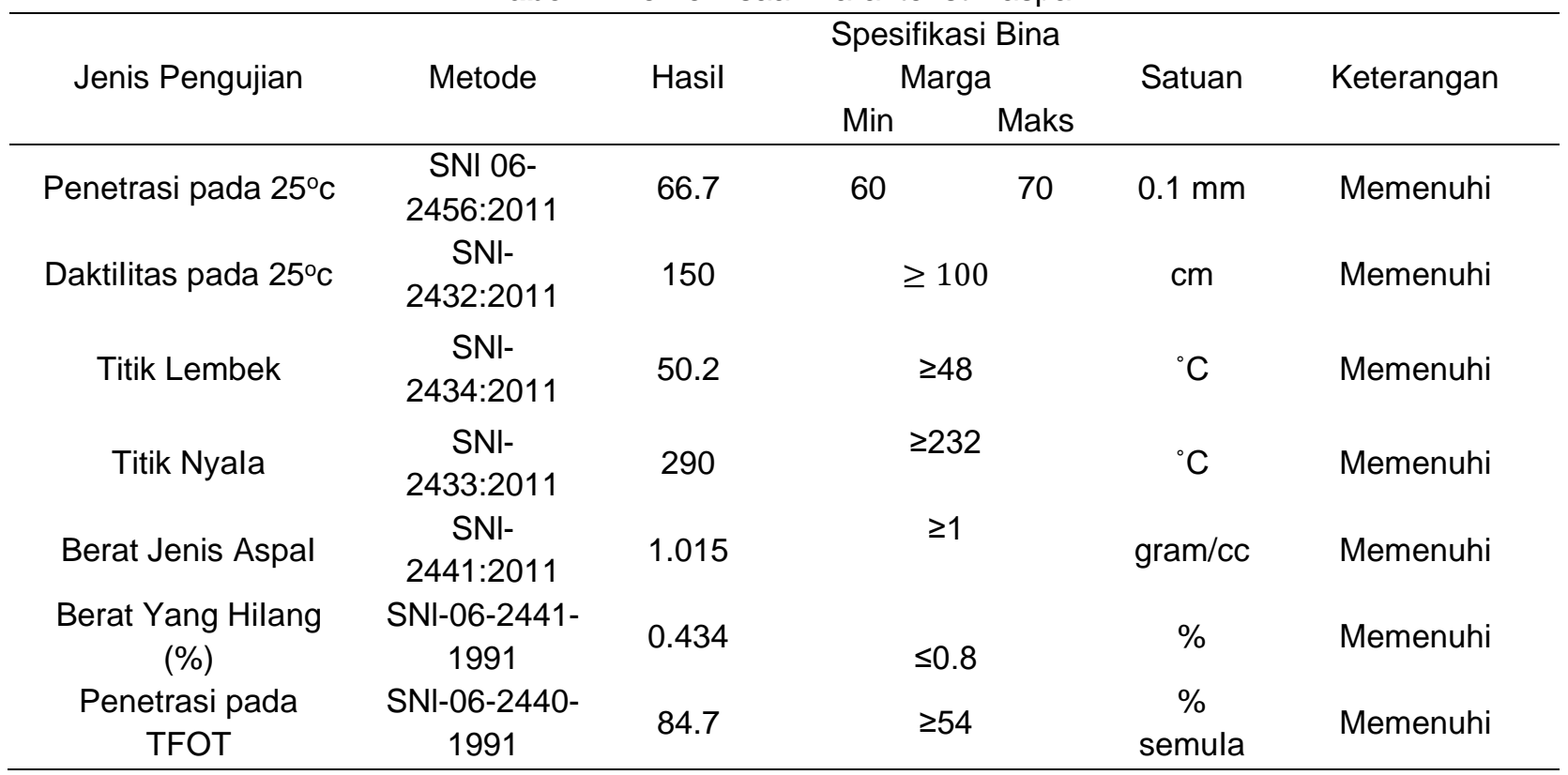

\section{Perancangan Campuran}

Sesuai dengan Spesifikasi Umum Bina Marga 2018 yaitu 5\%, 5,5\%, 6\%, 6,5\%, dan 7\%. Komposisi agregat kasar, agregat halus, dan filler untuk kadar aspal 5\% masing-masing 45,00\%, $49,00 \%$ dan $6,00 \%$. Komposisi agregat kasar, agregat halus, dan filler untuk kadar aspal 5,5\% masing-masing $45,00 \%, 49,00 \%$ dan $6,00 \%$. Komposisi agregat kasar, agregat halus, dan filler untuk kadar aspal 6\% masing-masing 45,00\%, $49,00 \%$ dan $6,00 \%$. Komposisi agregat kasar, agregat halus, dan filler untuk kadar aspal 6,5\% masing-masing $45,00 \%, 49,00 \%$ dan $6,00 \%$. Komposisi agregat kasar, agregat halus, dan filler untuk kadar aspal 7,00\% masing-masing $45,00 \%$, $49,00 \%$ dan $6,00 \%$.

\section{Pembuatan Benda Uji}

Menurut spesifikasi yang telah ditentukan oleh Bina Marga 2018 Untuk suatu campuran harus memenuhi semua standar spesifikasi. Pengujian ini dilakukan dengan alat Marshall Test dan jumlah benda uji serta penyiapan bahan campuran yang akan digunakan harus sesuai dengan komposisi campuran (Mix Design) yang telah diperoleh.

\section{Pengujian Marshall Konvensional}

Menurut ASTM D 1559-76 metode Marshall merupakan pemeriksaan stabilitas dan kelelehan/flow, serta untuk menganalisis suatu kepadatan dari pori campuran padat yang telah terbentuk serta benda uji dibentuk dari gradasi agregat campuran tertentu yang sesuai dengan spesifikasi campuran yang telah ada. [10]

\section{Penentuan Kadar Aspal Optimum}

Kadar aspal optimum diperoleh dari nilai terendah grafik hubungan Void In Mix VIM. Kadar aspal dalam campuran beton harus memenuhi semua kriteria atau karakteristik. Kadar aspal optimum berasal dari campuran yang dimana memiliki nilai Void In Mix (VIM) terkecil. 
Paulus Civil Engineering Journal

E- Jurnal Teknik Sipil UKI-Paulus Makassar

http://ojs.ukipaulus.ac.id/index.php/pcej

\section{Pengujian Marshall Immersion}

Dalam pengujian ini campuran diukur kinerja ketahanannya pada air panas dengan suhu $60^{\circ} \mathrm{C}$ selama 30 menit dan 24 jam.

\section{ANALISIS DAN PEMBAHASAN}

Stabilitas

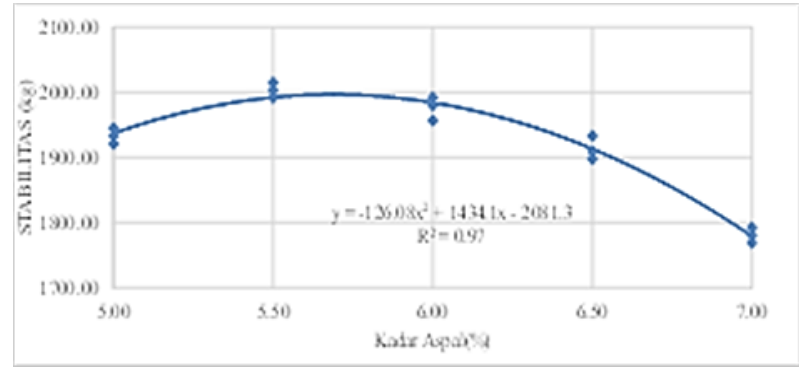

Gambar 2. Hubungan kadar aspal dan stabilitas

Berdasarkan grafik diatas persamaan garis $y=-126.08 x^{2}+1434.1 x-2081.3$. Stabilitas naik sebesar 1992,33 Kg dikadar aspal 5,5 \% dan kemudian kembali turun sebesar $1779,48 \mathrm{Kg}$ pada kadar aspal $7 \%$. Maksimal stabilitas berada pada kadar aspal 5,69\% dengan nilai stabilitas sebesar $1996,75 \mathrm{Kg}$.

Void in Mix (VIM)

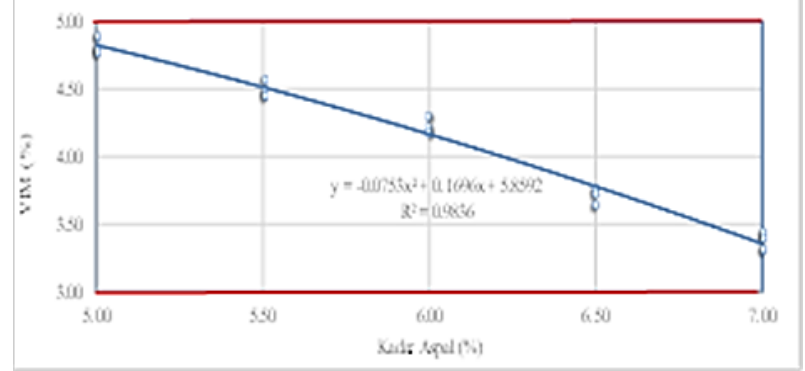

Gambar 3. Hubungan kadar aspal dan VIM

Berdasarkan grafik diatas persamaan garis $\mathrm{y}=$ $0.0753 x^{2}-0.1696 x+5.8592$. VIM turun dikadar aspal $7,39 \%$ kemudian VIM/Void In Mix berada dibatas minimumnya $3 \mathrm{~mm}$ pada kadar aspal $7 \%$ sedangkan, VIM/Void In Mix mencapai batas maksimum di $5 \mathrm{~mm}$ yang berada pada kadar aspal $4,69 \%$.

Flow
Volume 3 No.2, Juni, 2021

ISSN Online 2775-4529

ISSN Print 2775-8613

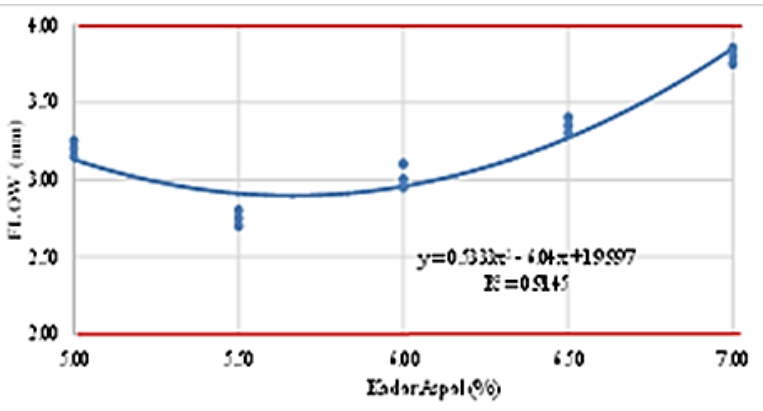

Gambar 4. Hubungan kadar aspal dan flow

Berdasarkan grafik diatas persamaan garis $y=0,5333 \times 2-6,04 x+19$. Flow turun dikadar aspal $5.50 \%$ lalu kemudian naik dikadar aspal $7 \%$. Flow minimal harus berada pada kadar aspal 5,66\% dengan nilai flow sebesar $2,90 \mathrm{~mm}$.

Void in Mineral Aggregate (VMA)

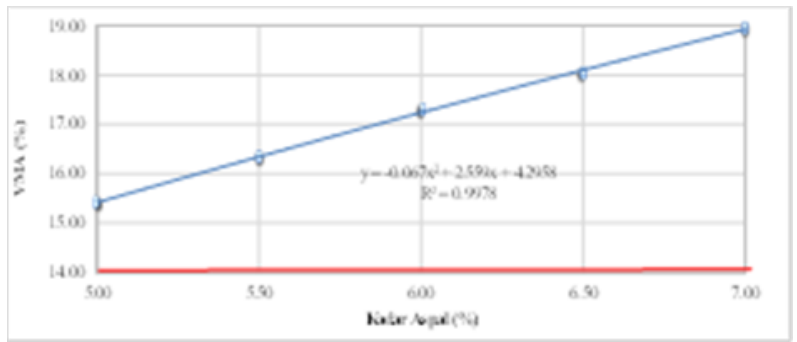

Gambar 5. Hubungan kadar aspal dan VMA

Berdasarkan grafik diatas persamaan garis

$y=-0.0672 x 2+2.3654 x+5$. VMA/ Void in Mineral Aggregate naik dikadar aspal 7\%. Kemudian VMA/ Void in Mineral Aggregate terkecil sebesar 14\% dikadar aspal 4,33\%.

Void Filled Bitument (VFB)

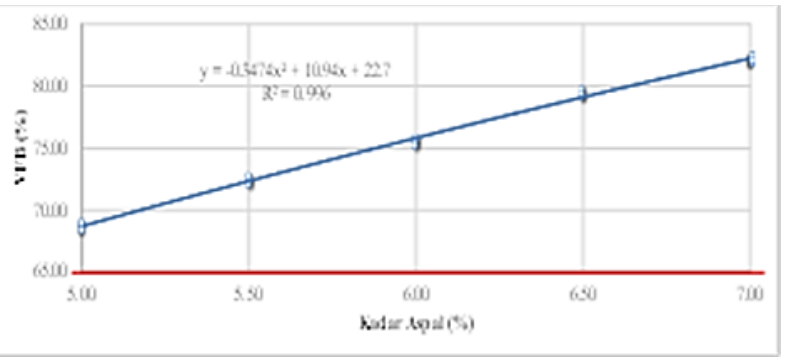

Gambar 6. Hubungan kadar aspal dan VFB

Berdasarkan persamaan garis menunjukan $y=-0.3119 x 2+11.337 x+18.975$. VFB/ Void Filled Bitument naik dikadar aspal $7 \%$. VFB/ Void Filled Bitument terkecil sebesar $65 \mathrm{~kg} / \mathrm{mm}$ dikadar aspal $4,1755 \%$.

\section{Penentuan Kadar Aspal Optimum}


Dari hasil analisis karakteristik campuran Laston Lapis Antara yang telah diuji di laboratorium, rentang kadar aspal yang akan digunakan yaitu $5,00 \%$ sampai $7,00 \%$.

\section{Stabilitas Marshall Sisa}

Menurut kadar aspal optimum yang akan digunakan adalah $5,50 \%$ lalu direndam di dalam waterbath \pm 24 jam yang berada pada suhu $\pm 60^{\circ} \mathrm{C}$ agar didapatkan nilai stabilitas Marshall sisa dari campuran.

Berdasarkan hasil pengujian Marshall Immersion didapatkan nilai stabilitas Marshall sisa 98,83\% dengan kadar aspal 5,5\%. Dari hasil pengujian tersebut agregat Gunung Sopai dalam campuran Laston Lapis Antara dapat tahan terhadap suhu.

Berdasarkan hasil pengujian karakteristik yang menggunakan agregat Gunung Sopai untuk setiap pengujian karakteristik agregat memenuhi pengujian karakteristik sesuai dengan ketentuan dari Spesifikasi Umum Bina Marga 2018. Berdasarkan rancangan komposisi pada campuran Laston Lapis Antara yang menggunakan agregat Gunung Sopai diperoleh kadar aspal optimum $5,50 \%$ dengan komposisi campuran agregat kasar $45,00 \%$, agregat halus $49,00 \%$, filler $6,00 \%$.

Tabel 3. Stabilitas marshall sisa untuk campuran laston lapis antara

\begin{tabular}{|c|c|c|c|}
\hline \multirow{2}{*}{$\begin{array}{l}\text { Persyaratan } \\
\quad \text { Kadar Aspal (\%) }\end{array}$} & \multicolumn{2}{|c|}{ Stabilitas } & \multirow{2}{*}{$\begin{array}{c}\text { Stabilitas Marshall } \\
\text { Sisa }\end{array}$} \\
\hline & Konvensional & Immersion & \\
\hline 5.5 & 2015.11 & 1968.24 & 97.67 \\
\hline 5.5 & 1991.68 & 1979.96 & 99.41 \\
\hline 5.5 & 2003.39 & 1991.68 & 99.42 \\
\hline Rata-rata & 2003.39 & 1979.96 & 98.83 \\
\hline Minimal & 1991.68 & 1968.24 & 97.67 \\
\hline Maksimal & 2015.11 & 1991.68 & 99.42 \\
\hline
\end{tabular}

\section{KESIMPULAN}

Karakteristik agregat, karakteristik aspal penetrasi 60/70 dan berat jenis filler dari Gunung Sopai, telah memenuhi spesifikasi untuk campuran Laston Lapis Antara.

Berdasarkan rancangan komposisi pada c ampuran Laston Lapis Antara yang menggunakan agregat Gunung Sopai diperoleh kadar aspal optimum 5,50\% dengan komposisi campuran agregat kasar $45,00 \%$, agregat halus $49,00 \%$, filler $6,00 \%$.

Karakteristik campuran Laston Lapis Antara melalui pengujian Marshall Konvensional diperoleh karakteristik campuran beraspal dan Marshall Immersion (Stabilitas Marshall Sisa) pada campuran Laston Lapis Antara yang menggunakan agregat dari Gunung Sopai memenuhi standar/spesifikasi Umum Bina Marga 2018, yaitu minimal $90 \%$.

\section{DAFTAR PUSTAKA}

[1] Yudi, Angga, dan Alpius, 2020, "Karakteristik Campuran AC-WC dan AC-BC Menggunakan Bahan Tambah Serat ljuk" Paulus Civil Engineering Journal. Volume.1, Nomor.2.

[2] Fani, Irianto, Alpius, (2019), "Pemanfaatan Agregat Sungai Wanggar Kabupaten Nabire Sebagai Bahan Campuran AC-WC dan ACBC" Paulus Civil Engineering Journal. Volume 1, Nomor.2.

[3] M. D. M. Palinggi dan Elizabeth, 2020 "Utilization of Lightweight Brick Waste Material As a Mixture of Laston AC - WC." J. of Physics, doi:10.1088/17426596/1464/1/012049

[4] Kusuma dan Rachman, 2018, "Study Characteristics of Nickel Slag For Gradient 
Paulus Civil Engineering Journal

E- Jurnal Teknik Sipil UKI-Paulus Makassar

http://ojs.ukipaulus.ac.id/index.php/pcej

Gap on Mixtured Hot Rolled Sheet Base," International Journal of Innovative Science, Engineering, and Technology Vol. 5, Issue 3

[5] D. P. Randelabi, Alpius dan R. Rachman, 2020, "Pengujian Karakteristik Campuran HRS-Base Menggunakan LGA Sebagai Pengganti Aspal Minyak," Paulus Civil Engineering Journal, Volume 2 Nomor.1.

[6] H. Nofrianto dan Z. Hendra (2014), "Kajian Campuran Panas Agregat Dengan Semen Sebagai Filler Berdasarkan Uji Marshall" Jurnal Momentum Volume. 16, Nomor.2.

[7] ASTM D 1559-76 Rancangan Campuran Metode Marshall
Volume 3 No.2, Juni, 2021

ISSN Online 2775-4529

ISSN Print 2775-8613

[8] Paretanan, E, 2020. Pengujian Karakteristik Campuran AC-BC Menggunakan Batu Sungai Masanda Kabupaten Tana Toraja.Skripsi Teknik Sipil, Universitas Kristen Indonesia Paulus, Makassar.

[9] Pata, J. I., 2020. Pengujian Karakteristik Campuran AC-BC Menggunakan Batu Sungai Bangkanase Kabupaten Toraja Utara. Skripsi Teknik Sipil, Universitas Kristen Indonesia Paulus, Makassar. 